\title{
Permeability of Modified Dentinal Surfaces
}

\author{
Manar M Abu Nawareg ${ }^{\text {ab }}$, Ola I Fahmy ${ }^{c}$, Gihan A Abdel Rahman', \\ Ahmed Z Zidan ${ }^{\text {de }}$, Nour A Habib ${ }^{b}$ \\ a Department of Restorative Dentistry, Biomaterials Division, Faculty of Dentistry, King Abdulaziz University, \\ Jeddah, Saudi Arabia \\ ${ }^{\mathrm{b}}$ Biomaterials Department, Faculty of Oral and Dental Medicine, Cairo University, Egypt \\ ${ }^{c}$ Department of Operative Dentistry, Faculty of Dentistry, Misr International University, Egypt \\ ${ }^{\mathrm{d}}$ Department of Restorative Dentistry, Biomaterials Division, Faculty of Dentistry, Umm Al-Qura University, \\ Mekkah, Saudi Arabia \\ ${ }^{\mathrm{e}}$ Biomaterials Department, Faculty of Dentistry, University of Moderrn Sciences and Arts (MSA), Egypt
}

Corresponding Author: Manar M Abu Nawareg

\begin{abstract}
Objectives: The aim of this study was to investigate the sealing ability of three adhesives bonded to modified dentinal surfaces after short and long storage periods.

Methods: Three adhesives were used in this study; two-step etch-and-rinse "Adper Single Bond 2", two-step self-etch "AdheSE" and one-step self-etch "G-Bond" adhesives. Modifications of the dentinal surface was performed by application of adhesives after oxalate application, application of adhesive after oxalate application to sodium hypochlorite $(\mathrm{NaOCl})$-deproteinized dentinal surface, compared to control groups (application of adhesive without any surface pretreatment). Dentinal sealing was investigated by measuring dentin permeability, using a fluid transport apparatus, after two storage periods; 24 hours and 2 months.
\end{abstract}

Results: After 24 hours, the control group bonded with "Adper Single Bond 2" without any surface treatment had the highest permeability (25.3\%) followed by "G-Bond" (16.2\%) and finally "AdheSE" $(11 \%)$. Significant reductions in permeability values were observed on application of oxalate in conjunction with both "Adper Single Bond 2" and "AdheSE" (11.7\% and 2.6\% respectively). Further significant reductions in permeability values of those two adhesives were noted when the combined $\mathrm{NaOCl}$ and oxalate pretreatments were used (5.7\% and $0.8 \%$ respectively). Permeability means for all groups increased after storage for 2 months.

Conclusions: Dentin surface deproteinization plus oxalate application produced the best dentin sealing for two step adhesives.

Keywords: Etch-and-rinse adhesives, self-etching adhesives, oxalate-desensitizing agent, $\mathrm{NaOCl}-$ deproteinizing agent, dentin permeability.

Clinical Significance: Although newly developed adhesive resins have attempted to improve dentin sealing, biodegradation of resin-dentin bonds over time jeopardize the durability of resin composite restorations with subsequent recurrent caries, discoloration and hypersensitivity.

\section{INTRODUCTION}

Adhesive dentistry should effectively restore the peripheral seal of dentin after enamel and/or cementum removal. Many resin composite restorations have been associated with postoperative sensitivity, impaired bond durability and occasional pulpal inflammation. This mainly occurs due to improper dentinal sealing, with subsequent movement of dentinal fluid in the dentinal tubules and bacterial products permeation through or around adhesive materials. Dentin adhesives should adhere firmly to the dentin and seal 
dentinal tubules as well as does enamel or cementum $^{[1-5]}$.

The assumption that adhesive-sealed dentin is impermeable to water movement has resulted in using adhesives to reduce cervical hypersensitivity via resin-occlusion of exposed dentinal tubules. Similarly, sealing of tooth preparations for indirect restorations with dentin adhesives has been advocated in fixed prosthodontics that involves the preparation of vital teeth. Of particular concern is whether these adhesives can be effectively employed for eliminating dentinal fluid movement in freshly exposed, vital deep dentin that is close to pulp horns, where the contribution of a positive pulpal pressure is expected to be high ${ }^{[6]}$.

Dentin bonding has been evolving rapidly to include the use of hydrophilic adhesive monomers to ensure that contemporary dentin adhesives are compatible with the intrinsic wetness of acid-etched dentin. Thus, adhesive monomers have been modified to contain both hydrophilic and hydrophobic moieties. By virtue of these modifications, adhesives have an increased potential for water sorption especially, contemporary highly hydrophilic adhesives ${ }^{[6-9]}$. Water sorption by hydrophilic resin monomers within both the hybrid and adhesive layers has been considered to contribute to the degradation of resin-dentin interfaces over time ${ }^{[4,7,10 \text {, }}$ 11].

The use of oxalate desensitizers has been suggested in an attempt to reduce the hydraulic conductance through the dentinal tubules. However, this effect may be temporary as surface crystals of calcium oxalate are solubilized by oral fluids and may be removed by daily brushing ${ }^{[12-18]}$. Adhesive resin comonomers have also been advocated for occluding exposed dentinal tubules. However, they usually form a weak thin layer on top of the dentinal surface which can be also lost by daily brushing. The loss of the surface layer of resin during oral hygiene activities should not permit a return to dentin sensitivity if residual resin tags remain occluding the tubules. Unfortunately, defective hybridization as well as polymerization shrinkage of resin produce leaky resin tags ${ }^{[19]}$. Furthermore, resin tags may hydrolytically degrade over time, causing the development of a gap between the tag and the surrounding tubule, allowing sufficient fluid shifts to cause dentin sensitivity $[15,20,21]$. Thus, in an attempt to improve bond durability and reduce dentin sensitivity, oxalate occlusion of dentinal tubules was combined with resin occlusion. This combination was more effective than either treatment alone ${ }^{[15,22]}$.

Due to the hydrophilic nature of collagen, the hybrid layer has a hydrogellike behavior, absorbing and releasing water [8]. This may be responsible for the degradation of resin-dentin interfaces ${ }^{[9,23-27}$, 28]. Thus, application of sodium hypochlorite to acid-etched dentin was suggested to remove collagen fibrils and their bound water from the bonded interface.

The aim of the current study was to investigate methods of reduction of water flux through dentinal tubules, modification of the hydrophilic content of the dentin substrate and the use of a more hydrophobic adhesive in an attempt to improve its sealing capacity. This may have an impact on improved bond durability with subsequent reduction in hypersensitivity and increase in the survival rate of resin composite restorations. The null hypothesis tested was that the different dentin surface treatments, used in this study, do not affect the sealing ability of the three tested adhesives.

\section{MATERIALS AND METHODS Permeability Test}

A total of ninety freshly extracted, sound human unerupted third molars were selected and used in this study. All soft tissues were removed and the teeth were stored in distilled water at $4^{\circ} \mathrm{C}$ for no longer than one month prior to specimen preparation.

Ninety coronal deep dentin discs were prepared using a diamond disc (K6974 
Komet, Germany) mounted on a conventional speed straight handpiece (W \& $\mathrm{H}$, Austria) under continuous water irrigation. Deep dentin was selected as it is considered the most permeable dentin due to its dense large diameter tubules ${ }^{[29]}$. Crowns of the selected teeth were separated from their root segments. The crown segments were ground gradually from the pulpal side, perpendicular to the long axis of the tooth until the pulp horns completely disappeared (to avoid variation in sample morphology). Then, grinding was performed on the occlusal side until the thickness of the discs was reduced to $1 \mathrm{~mm}(+0.1 \mathrm{~mm})$.

Both surfaces (pulpal and occlusal) of each dentin disc were abraded with 600 grit silicon carbide paper under water irrigation for 30 seconds, to create a standardized smear layer. The prepared discs were stored in distilled water until the bonding procedure was performed within 3 days.

\section{Permeability apparatus:}

A fluid transport apparatus was used to test the permeability of the dentin discs (Fig. 1a,b). The apparatus was constructed according to the device designed by Pashley and Galloway ${ }^{[30]}$, with slight modifications. The apparatus was connected to an electric pump with a rubber tube to provide controlled pulpal pressure $(15 \mathrm{~cm} \mathrm{H} 2 \mathrm{O}),{ }^{[2,3}$, 29] which was regularly checked using a sphygmomanometer.

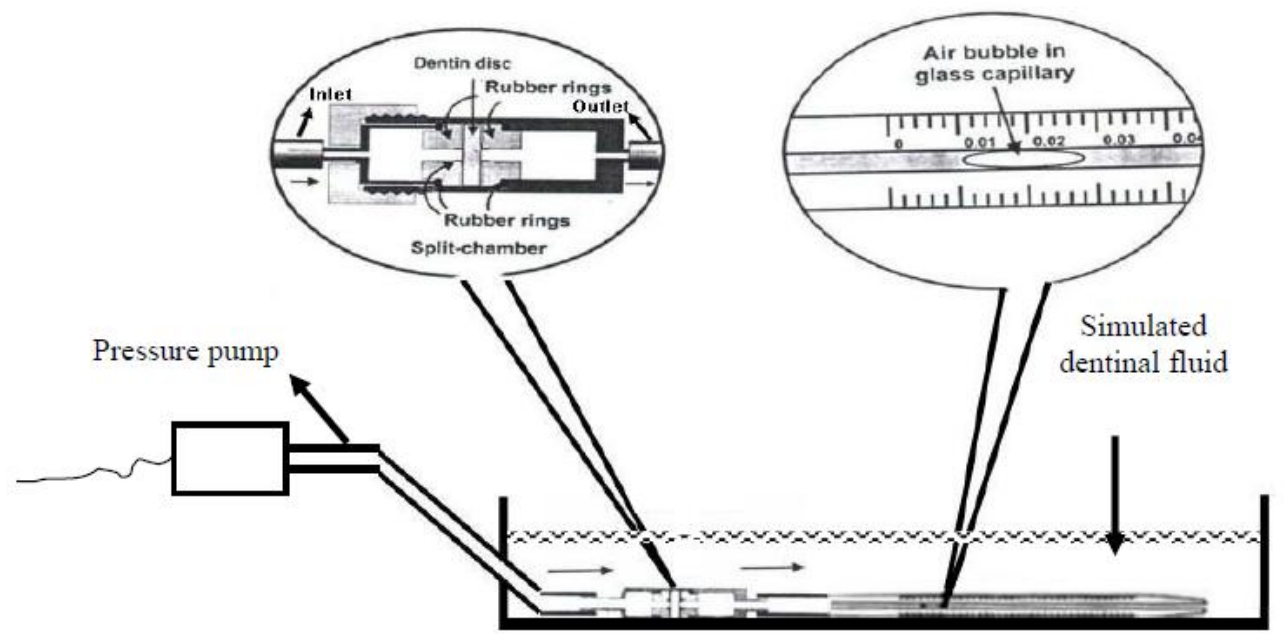

Figure 1(a): Diagram of fluid transport apparatus assembly

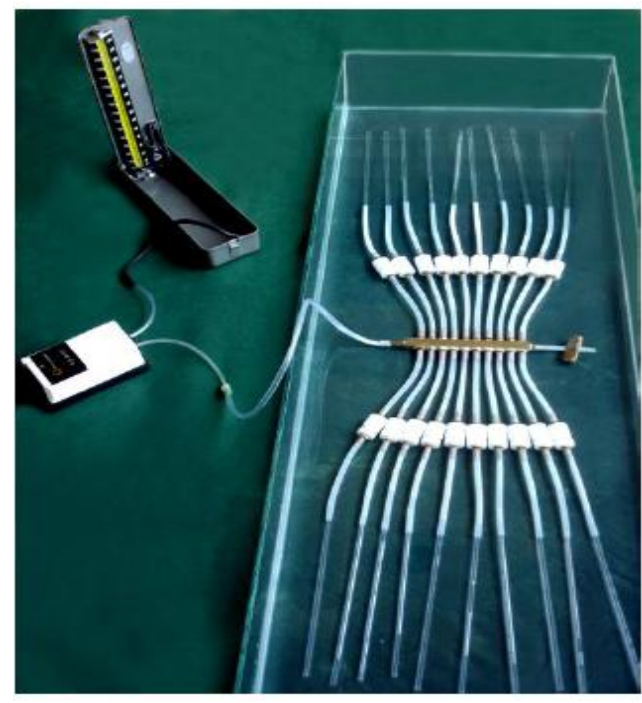

Figure 1(b): Fluid transport apparatus assembly
The fluid transport apparatus included ten pairs of split-Teflon chamber devices, each consisting of two parts, female and male parts which were screwed together (Fig. 1a). A pair of identical rubber "O" rings, with a central hole $(0.5 \mathrm{~cm}$ in diameter), were used to limit the tested surface area of each dentin disc. The apparatus was immersed in a simulated dentinal fluid (Dr. Peter Shellis' artificial saliva, Table 1). Care was taken to fill all the inner parts of the assembly with the simulated dentinal fluid to displace all air bubbles. 


\section{Mechanism of measuring the dentin permeability:}

Dentin permeability was measured by tracing the displacement of an air bubble within the glass capillaries, inserted into the outflow of the split-chamber devices (Fig. 1 a), using a millimeter scale ${ }^{[3,13,15,30,31]}$.

\section{A- Measurement of Pre-treatment Fluid Filtration (baseline value):}

All discs were etched on both sides with $35 \%$ phosphoric acid gel for 15 seconds and then rinsed with water. After all the discs were mounted into their split chambers, the air bubble location was determined for every specimen and recorded.

Pressure was applied for one hour, and the movement of the air bubble was redetermined and recorded. Then, the linear displacement of the air bubble in the horizontally positioned glass capillary tube was calculated. Dentin permeability varies considerably among different teeth, therefore, discs with extremely high or low permeability were excluded.

Baseline fluid flow (Q) was derived from the linear displacement of the air bubble, depending on the volume of the pipette, using the following equation:-

$\mathrm{Q}=$ displacement $\times$ cross sectional area of the pipette.

Permeability was expressed in terms of fluid filtration $(\mathrm{Jv})^{[22,32,33]}$ where:

$\mathrm{Jv}=\mathrm{Q} / \mathrm{At}$

$\mathrm{JV}=$ fluid filtration rate in $\mu 1 \mathrm{~cm}-2 \mathrm{~min}-1$

$\mathrm{Q}=$ fluid flow in $\mu \mathrm{l}$.

$\mathrm{A}=$ dentinal (or $\mathrm{O}$ ring central hole) surface area in $\mathrm{cm} 2$

$\mathrm{t}=$ time in minutes.

Baseline fluid filtration represents the maximum fluid flow of each specimen and was assigned a value of $100 \%$ permeability.

\section{B-Surface treatment of the specimens:}

After recording the baseline fluid filtration, the discs were removed from the split chambers. The occlusal side of each disc was polished using 600 grit silicon carbide paper for 30 seconds, under water irrigation to recreate a uniform smear layer. All samples were randomly divided into three groups (30 each) according to the adhesive system used; 1) Etch-and-rinse adhesive (Adper Single Bond 2); 2) Twostep, self-etch primer/adhesive (AdheSE); 3) One-step, self-etch adhesive (G-Bond). Each group was randomly subdivided into three subgroups (10 specimens each) according to the surface pretreatment performed: 1) Adhesive alone (Control- no surface pretreatment); 2) Oxalate pretreatment; 3) $\mathrm{NaOCl}$ and oxalate pretreatment. The compositions of the materials used in this study are presented in table 1.

For the control specimens, each adhesive system was applied according to its manufacturer's instructions without any surface pretreatment (Table 1).

For the specimens in the oxalate pretreatment subgroups, $3 \%$ monopotassium monohydrogen oxalate desensitizing agent (Bisblock, Bisco Inc, USA) was applied on the occlusal dentinal surface for 30 seconds as follows; after acid-etching in the Adper Single Bond 2 group or after self-etch priming in the AdheSE group or applied on smear layer-covered dentin before application of G-Bond adhesive. Then, the treated dentin surfaces were rinsed with water and were blot-dried, except for the specimens of the AdheSE group, they were air-dried only. Subsequent adhesive application was performed according to manufacturers' instructions.

For the specimens receiving sequential $\mathrm{NaOCl}$ and oxalate treatment, $5.25 \% \mathrm{NaOCl}$ dentin deproteinizer was applied on the occlusal dentinal surface for 2 minutes, after acid-etching in the Adper Single Bond 2 group and on smear layercovered dentin in the AdheSE and G-Bond groups. The dentin surfaces of all specimens were rinsed thoroughly for 30 seconds then were blot-dried. This was followed by oxalate application and finally the adhesive application in the Adper Single Bond 2 group. In the AdheSE group, the self-etch 
primer was applied to the deproteinized dentin surface followed by oxalate application and finally the adhesive was applied. In the G-Bond group, the oxalate was applied on the deproteinized smear layer-covered dentin then the adhesive was finally applied. All specimens were then stored in simulated dentinal fluid at $37^{\circ} \mathrm{C}$ for 24 hours and for 2 months.

\section{C-Measurement of Post-treatment Fluid Filtration:}

Each treated disc was remounted in its specific chamber and the fluid filtration of bonded dentin, after each storage period, was measured exactly as the baseline measurement was performed. The dentin permeability of each resin-bonded specimen of all groups after each storage period was obtained using the following equation ${ }^{[31,32]}$ :

$\% \mathbf{P}=\frac{\text { Fluid filtration rate of resin-bonded dentin }}{\text { Baseline fluid filtration rate of etched dentin }} \times 100$

This represents the permeability exhibited by the resin-bonded dentin relative to its maximum acid etched value, with each specimen serving as its own control.

\section{Statistical Analysis:}

Data management and analysis were performed using Statistical Package for Social Sciences (SPSS) vs. 17. Data were summarized using means and standard deviations. Comparisons between groups were done using three-way analysis of variance (ANOVA) with repeated measures as one factor, surface treatment as the second factor and adhesives as the third factor. All p-values are two-sided. P-values $\leq 0.05$ were considered significant.

\section{RESULTS \\ Permeability measurements:}

There were three different adhesives tested: 1) The etch-and-rinse primer/adhesive blend, Adper Single Bond 2 ; 2) the two-step, self-etching primer + neat adhesive, AdheSE; 3) the single-step, single bottle, self-etching adhesive, G-Bond (Table 1). There were three different surface treatments with each adhesive group. The pretreatment variables were: 1) control- no pretreatment, just adhesive application; 2) pretreatment with $3 \%$ potassium oxalate for $30 \mathrm{sec}$, followed by adhesive application; 3) pretreatment with $5.25 \% \mathrm{NaOCl}$ for $2 \mathrm{~min}$, rinsed, followed by oxalate treatment, followed by bonding.

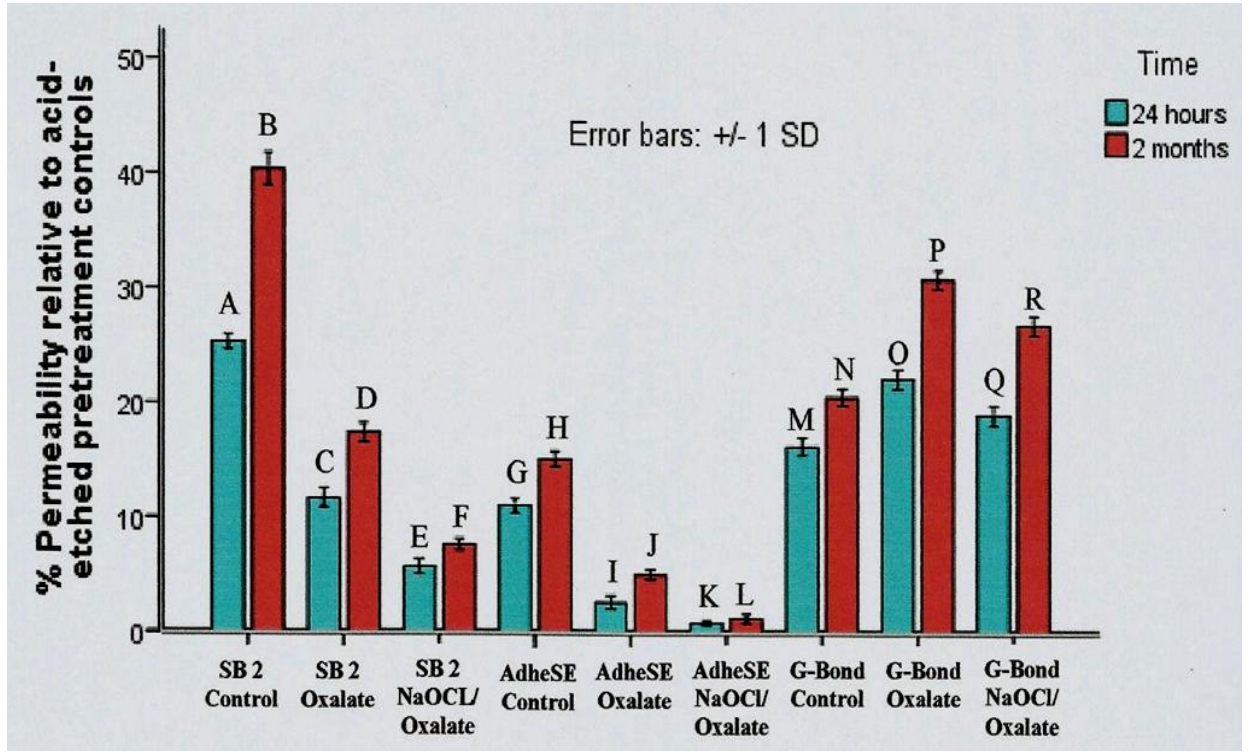

Figure 2: Post-treatment permeability of dentin specimens treated with Single Bond 2, AdheSE, or G-Bond, with no treatment (controls), oxalate, or $\mathrm{NaOCl} /$ oxalate pretreatments, measured after 24 hours and 2 months. Bars identified by different pairs of letters are significantly different at $\mathrm{p}<\mathbf{0 . 0 5}$. Only AdheSE pretreated with $\mathrm{NaOCl}$ and oxalate showed minimal increase in permeability over 2 months. The post-treatment permeability in that group was almost zero. Values are means $\pm S D, n=10$. 
In the control groups for Single Bond 2, where no pretreatment of the dentin surface was made except for acid-etching dentin with $37 \%$ phosphoric acid for $15 \mathrm{sec}$, followed by rinsing with water for $10 \mathrm{sec}$ and applying two layers of Adper Single Bond 2 , the initial $24 \mathrm{~h}$ permeability was relatively high (Fig. 2, Table 2). That is, the bonded dentin permitted $25.3 \pm 0.7 \%$ as much fluid flow as acid-etched, uncovered controls had permitted. Within 2 months of storage in a buffer, the permeability of Single Bond 2 bonded specimens increased significantly $(p<0.05)$ to $40.4 \pm 1.4 \%$ of control values.

When acid-etched dentin was treated with $3 \%$ potassium oxalate for $30 \mathrm{sec}$ and then rinsed with water, briefly dried and then moist bonded with Single Bond 2, the $24 \mathrm{~h}$ permeability of the bonded specimens was only $11.7 \pm 0.8 \%$ as much fluid flow as the acid-etched, uncovered controls had been. Two months later, the permeability value had increased $(\mathrm{p}<0.05)$ to $17.4 \pm$ $0.8 \%$.

When acid-etched dentin surfaces were treated with $5.25 \% \mathrm{NaOCl}$ for $2 \mathrm{~min}$, rinsed for $30 \mathrm{sec}$, then treated with $3 \%$ potassium oxalate for $30 \mathrm{sec}$, rinsed and then bonded with Single Bond 2, the $24 \mathrm{~h}$ permeability values were only $5.7 \pm 0.6 \%$ as much as was the acid-etched control value (100\%). The 2 month permeability values were not much changed from the $24 \mathrm{~h}$ values (Fig. 2, Table 2).

When AdheSE primer was used on smear layer-covered dentin, followed by application of the neat adhesive, the $24 \mathrm{~h}$ permeability values $11.0 \pm 0.6 \%$ was only half that of the Adper Single Bond 2 control values (Fig. 2, Table 2). After storage for 2 months, the AdheSE values increased slightly to $15.1 \pm 0.7 \%$.

When the AdheSE primer-covered dentin was treated with $3 \%$ potassium oxalate for $30 \mathrm{sec}$, before application of the neat adhesive, the $24 \mathrm{~h}$ permeability values were only $2.60 \pm 0.59 \%$ of acid-etched controls. After 2 months, that value increased to $5.00 \pm 0.42 \%$.
However, when smear layer-covered dentin was treated with $5.25 \% \mathrm{NaOCl}(2$ min), followed by AdheSE primer, then 3\% potassium oxalate, followed by the neat adhesive, the $24 \mathrm{~h}$ permeability value was only $0.80 \pm 0.24 \%$, the lowest permeability value measured in the experiment, indicating near-perfect sealing. Two months later, the permeability value only increased to $1.20 \pm 0.37 \%$, the lowest 2 month permeability value in the study.

When G-Bond adhesive was bonded to untreated control smear layer-covered dentin, the $24 \mathrm{~h}$ permeability values were $16.2 \pm 0.8 \%$. After storage for 2 months, the G-Bond values increased to $20.5 \pm 0.7 \%$.

However, when the smear layercovered dentin was treated with $3 \%$ potassium oxalate and then bonded with GBond, the post-treatment permeability value, $22.1 \pm 0.9 \%$, was higher than in the notreatment control condition, $16.2 \pm 0.8 \%$ (Fig. 2 and Table 2), suggesting that oxalate treatment decreased the self-etching adhesive's ability to seal dentin. Furthermore, two months later, the permeability value had increased $(\mathrm{p}<0.05)$ from $22.1 \pm 0.9 \%$ to $30.8 \pm 0.8 \%$.

Similarly, when the smear layercovered dentin surface was treated sequentially with $\mathrm{NaOCl}$ and potassium oxalate, prior to bonding, the G-Bond $24 \mathrm{~h}$ permeability values were again, higher than the untreated control group (compare $18.9 \pm$ 0.9 to $16.2 \pm 0.8 \%$ - Fig. 2, Table 2) with further increase after 2 months to $26.8 \pm$ $0.9 \%$, indicating that G-Bond did not seal dentin very well.

\section{DISCUSSION}

The permeability results of this study indicated that when no surface pretreatment was applied, the two-step etchand-rinse Single Bond 2 adhesive exhibited the greatest post-treated residual dentin permeability compared with the two tested self-etch adhesives. These results were in agreement with other reports ${ }^{[5,32-34]}$. The high permeability of Adper Single Bond 2 adhesive may be attributed to smear layer 
removal prior to bonding which opens up the dentinal tubules and exposes the collagen matrix after rinsing off the etchant, increasing dentinal fluid flow.

Furthermore, the high permeability of Single Bond 2 bonds may also be attributed to incomplete resin penetration into the deeply etched dentin due to the use of a separate aggressive phosphoric acid etch causing over-etching ${ }^{[35]}$. Moreover, as the two-step etch-and-rinse Single Bond adhesive utilized a rinsing step and was applied according to manufacturer's instructions, using the wet bonding technique, incomplete water removal from the deeply etched dentin might have resulted in the "overwetting phenomenon" [36]. After etching with phosphoric acid and rinsing with water, dentin has a water content of 70 vol. $\%{ }^{[9]}$. The single bottle system includes a mixture of hydrophilic and hydrophobic groups as well as solvents that allow more water seepage than neat, solvent free adhesives like AdheSE adhesive (Table 1).

Table 1: Materials used, their composition, application procedure and manufacturer.

\begin{tabular}{|c|c|c|c|}
\hline Material & Composition & Application Procedure & Manufacturer \\
\hline $\begin{array}{l}\text { Adper } \\
\text { Single Bond } 2 \\
\text { (Two-Step } \\
\text { Etch-and- } \\
\text { Rinse) }\end{array}$ & $\begin{array}{l}\text { Etchant: } 37 \% \text { phosphoric acid gel. } \\
\text { Adhesive : BIS-GMA }{ }^{\bullet} \text {, HEMA }{ }^{\Theta} \text {, } \\
\text { dimethacrylate, water, ethanol, copolymer of } \\
\text { polyalkenoic acid and polyitaconic acid, } \\
\text { colloidal silica nanofiller, camphorquinone. }\end{array}$ & $\begin{array}{l}\text { Etchant: Apply etchant for } 15 \text { seconds, rinse } \\
\text { for } 10 \text { seconds and blot dry excess water } \\
\text { leaving a glistening surface. } \\
\text { Adhesive: Apply } 2 \text { consecutive coats of } \\
\text { adhesive with gentle agitation for } 15 \text { seconds, } \\
\text { air thin gently for } 5 \text { seconds and light cure* } \\
\text { for } 10 \text { seconds. }\end{array}$ & $\begin{array}{l}\text { 3M ESPE, Dental } \\
\text { Products, St. Paul, } \\
\text { MN, U.S.A. }\end{array}$ \\
\hline $\begin{array}{l}\text { AdheSE } \\
\text { (Two-Step } \\
\text { Self-Etch) }\end{array}$ & $\begin{array}{l}\text { Self-etching primer: Phosphonic acid acrylate, } \\
\text { dimethacrylate, initiators, stabilizers, water. } \\
\text { Adhesive: HEMA, dimethacrylate, } \\
\text { highly dispersed silicon dioxide, } \\
\text { initiators and stabilizers. }\end{array}$ & $\begin{array}{l}\text { Self-etching primer: Apply self-etching } \\
\text { primer for } 30 \text { seconds with brushing action, air } \\
\text { thin strongly for } 5 \text { seconds. } \\
\text { pH }=1.4 \\
\text { Adhesive: Apply adhesive, air thin gently and } \\
\text { light cure* for } 10 \text { seconds. }\end{array}$ & $\begin{array}{l}\text { Ivoclar-Vivadent AG, } \\
\text { FL-9494 } \\
\text { Schaan / } \\
\text { Liechtenstein }\end{array}$ \\
\hline $\begin{array}{l}\text { G-Bond } \\
\text { (One-Step } \\
\text { Self-Etch) }\end{array}$ & $\begin{array}{l}\text { 4-MET }{ }^{\square} \text {, phosphoric ester monomer, } \\
\text { UDMA }^{\text {ss, }} \text { acetone, water, silica nano-filler, } \\
\text { camphorquinone. }\end{array}$ & $\begin{array}{l}\text { Apply one coat of adhesive on dentin surface. } \\
\text { Leave undisturbed for } 10 \text { seconds, strong air } \\
\text { drying for } 5 \text { seconds. } \mathrm{pH}=2 \text {. Light cure* for } \\
10 \text { seconds. }\end{array}$ & $\begin{array}{l}\text { GC Corp. } \\
\text { Tokyo, Japan }\end{array}$ \\
\hline Bisblock & $\begin{array}{l}3 \% \text { monopotassium monohydrogen oxalate } \\
\text { desensitizing solution, } \mathrm{pH}=2.5 \text {. }\end{array}$ & Apply on dentinal surface for $30 \mathrm{sec}$. & $\begin{array}{l}\text { Bisco Inc. } \\
\text { Schaumberg IL, U.S.A. }\end{array}$ \\
\hline $\begin{array}{c}\text { Dr. Peter } \\
\text { Shellis' } \\
\text { artificial saliva }\end{array}$ & 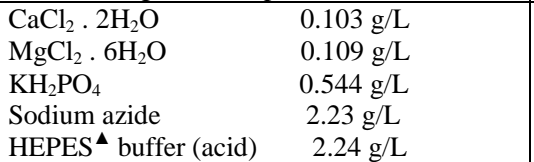 & & $\begin{array}{l}\text { Arcos Organics } \\
\text { New Jersey, U.S.A. } \\
\text { Mallinckrodt Baker, } \\
\text { Inc. Phillipsburg, NJ, } \\
\text { U.S.A. }\end{array}$ \\
\hline \multicolumn{4}{|c|}{$\begin{array}{l}\text { •BIS-GMA: Bisphenol A glycidyl dimethacrylate. } \\
\text { 'HEMA : hydroxyethyl methacrylate. } \\
\text { 4-MET: } 4 \text { methacryloxyethyl trimellitic acid.. } \\
\text { EDMA : urethane dimethacrylate monomer. } \\
\text { ES : N-2-Hydroxyethylpiperazine-N'-2-ethanesulfonic acid. } \\
\quad \text { * Mini LED, } 1250 \mathrm{~mW} / \mathrm{cm}^{2} \text {, Satelec, Acteon. }\end{array}$} \\
\hline
\end{tabular}

Since water is the main causative factor in degradation of resin-dentin interfaces, complete or partial blockage of the dentinal fluid flow from the underlying dentin may improve dentinal sealing. This was evident by the significant decrease in permeability results obtained using Single Bond 2 adhesive, in conjunction with oxalate pretreatment, in agreement with Yiu et al. ${ }^{[22]}$. The oxalate desensitizer was used after acid etching which might have resulted in subsurface precipitation of calcium oxalate crystals occluding the dentinal tubules. At the same time subsurface precipitation of calcium oxalate crystals did not interfere with resin penetration into the dentinal surface. Furthermore, the resin tags may seal the calcium oxalate crystals in place, avoiding the solubilizing effect of oral fluids. Such combined treatment was advised in several research reports ${ }^{[14,16-18,}$ $20,30,36]$

The permeability results showed further significant decreases in dentin permeability when Single Bond 2 adhesive was used in conjunction with oxalate, after deproteinization with $\mathrm{NaOCl}$, indicating that this combination produced better dentin 
sealing. This may be due to elimination of most of the exposed collagen within the dentin surface. As collagen has a low surface energy and a high water content, its removal would improve the wettability of the dentin surface. The collagen fibrils also contain the endogenous proteases of dentin that are responsible for the slow hydrolysis of hybrid layers ${ }^{[9,23]}$. The use of $\mathrm{NaOCl}$ destroyed and solubilized those matrix metalloproteinases (MMPs). Consequently, the possibility of incomplete resin penetration into etched dentin with subsequent defective hybridization, responsible for deterioration of dentin bonding, may be eliminated or reduced ${ }^{\text {[38- }}$ ${ }^{42]}$. These results require rejection of the test null hypothesis that different surface treatments do not affect the sealing properties of adhesive systems.

Deproteinization of etched-dentin might have resulted in an increase in the number and diameter of opened dentinal tubules leading to an increase in the number and diameter of resin tags which may improve the bonding efficiency ${ }^{[39,41,43,44]}$. Prati et al. called this resin-rich, collagenpoor resin-dentin interface a "reverse hybrid layer" ${ }^{[45]}$.

The cumulative effect of phosphoric acid and $\mathrm{NaOCl}$ treatment on dentin resulted in larger dentinal tubules diameters which might have made it difficult for oxalate crystals to completely occlude the dentinal tubules, making the interface more permeable to fluid flow. It is desirable to have less porous dentin to provide better possibility for dentinal sealing. However, using Single Bond 2 after etching, $\mathrm{NaOCl}$ and oxalate treatment might have resulted in resin penetration and integration between the calcium oxalate crystals, reducing permeability of Single Bond 2 bonded dentin surfaces to their lowest values (Table 2).

The introduction of the self-etch technique eliminated many techniquesensitive factors related to the etch-andrinse technique ${ }^{[35]}$. This involves elimination of the separate etch and rinse steps and lowers the water content of selfetched dentin compared to etch-and-rinse adhesives. The weak acidity of self-etch adhesives only modified the smear layer and plugs rather than completely removing them, leaving dentin permeability very low and providing better sealing [30, 46-50]. Furthermore, self-etch adhesives superficially demineralize the underlying dentin, providing a continuous hybrid layer with less unpolymerized hydrophilic monomers. Several previously published studies support those results [37, 48, 50, 51]. Incomplete resin penetration is less likely due to simultaneous etching and priming of dentin to the same depth via the same acidic monomer which eliminates the need to rewet dentin or re-expand shrunken collagen $[42,49,52]$

However, the permeability results of the current study showed that when no surface pretreatment was applied, self-etch adhesives created resin-dentin bonds that were still permeable to fluid flow. This may be attributed to the fact that these adhesives contain increased concentrations of hydrophilic resin monomers to facilitate their penetration into the hydrophilic dentin surface. This would, in turn, increase their capacity for water sorption. Also, AdheSE and G-Bond contain 25- 35\% water to reduce viscosity and to ionize the acidic monomer to be able to demineralize the underlying dentin ${ }^{[53-55]}$. Residual water retained within the bonded interface contributes to increased permeability of adhesives to fluid flow. This was in agreement with several studies that have reported that self-etch adhesives behave as semi-permeable membranes after polymerization ${ }^{[5,21,35,49,56]}$.

The permeability of self-etch adhesives may be also attributed to the presence of the calcium salts of the acidic monomers and calcium phosphates, derived from demineralization of dentin (as no rinsing was performed), as well as uncured hydrophilic resin monomers. All these factors decrease the local water concentration, creating an osmotic pressure 
gradient that initiates water movement from the underlying dentin through the cured selfetch adhesives ${ }^{[10,56,57]}$.

It is worth noticing that the permeability of the two-step self-etch AdheSE adhesive was significantly lower than the other two tested adhesives. The improved sealing capacity of the neat AdheSE adhesive may be attributed to the presence of a separate layer of solvent-free, relatively hydrophobic, less permeable bonding resin placed over primed dentin. This layer might have limited the diffusion of water from the underlying dentin through the hybrid layer, decreasing water sorption and providing better dentinal sealing $[5,33,34$, 56]. Furthermore, it was reported that the application of a separate neat adhesive as a separate step may provide sufficient time for proper water/solvent evaporation and proper resin penetration ${ }^{[58]}$.

Table 2: Permeability means and standard deviations (SD) exhibited by each adhesive system after different surface treatments at the two testing periods.

\begin{tabular}{|c|c|c|c|c|c|}
\hline Adhesive System & Surface Treatment & \multicolumn{2}{|c|}{24 hours } & \multicolumn{2}{|c|}{2 months } \\
\cline { 3 - 6 } & & Mean & SD & Mean & SD \\
\hline \multirow{3}{*}{$\begin{array}{c}\text { dper } \\
\text { Single Bond } 2\end{array}$} & No pretreatment & $25.3^{\mathrm{I}}$ & 0.7 & $40.4^{\mathrm{i}}$ & 1.4 \\
\cline { 2 - 6 } & Oxalate + Adhesive & $11.7^{\mathrm{E}}$ & 0.8 & $17.4^{\mathrm{e}}$ & 0.8 \\
\cline { 2 - 6 } & NaOCl/oxalate/ adhesive & $5.7^{\mathrm{C}}$ & 0.6 & $7.6^{\mathrm{c}}$ & 0.5 \\
\hline \multirow{3}{*}{ AdheSE } & No pretreatment & $11.0^{\mathrm{D}}$ & 0.6 & $15.1^{\mathrm{d}}$ & 0.7 \\
\cline { 2 - 6 } & Oxalate + Adhesive & $2.60^{\mathrm{B}}$ & 0.59 & $5.00^{\mathrm{b}}$ & 0.42 \\
\cline { 2 - 6 } & NaOCl/oxalate/ adhesive & $0.80^{\mathrm{A}}$ & 0.24 & $1.20^{\mathrm{a}}$ & 0.37 \\
\hline \multirow{3}{*}{ G-Bond } & No pretreatment & $16.2^{\mathrm{F}}$ & 0.8 & $20.5^{\mathrm{f}}$ & 0.7 \\
\cline { 2 - 6 } & Oxalate + Adhesive & $22.1^{\mathrm{H}}$ & 0.9 & $30.8^{\mathrm{h}}$ & 0.8 \\
\cline { 2 - 6 } & NaOCl/oxalate/ adhesive & $18.9^{\mathrm{G}}$ & 0.9 & $26.8^{\mathrm{g}}$ & 0.9 \\
\hline
\end{tabular}

Values represent the post-treatment values of dentin permeability expressed as a percent of untreated acid-etched controls. For instance, a value of $25.3 \pm 0.7 \%$ means that bonding with Single Bond reduced dentin permeability 100-25.3= 74.7 percent, leaving the bonded dentin $25.3 \%$ as permeable as the untreated control value for that disc. Groups identified by different letters are significantly different at $p<0.05$. Values are mean $\pm S D(\%), n=10$.

The permeability test results (Table 2) showed that when oxalate was applied following the self-etching AdheSE primer application, significantly lower permeability with better dentin sealing was obtained. This may be attributed to the potential interaction that might have occurred between the oxalate solution and the dissolved calcium ions present within the resin (since they are not washed away) producing insoluble oxalate crystals. These crystals might have occupied the microscopic spaces within the hybrid layer and penetrated into the tubules to participate in resin tag formation providing better integration and sealing. Furthermore, these crystals were precipitated within the resin layer so they were more protected from the dentinal fluid than those precipitated within the tubules that were in direct contact with the fluid.

The lowest dentin permeability was obtained when the smear layer-covered dentin was treated with $\mathrm{NaOCl}$, followed by self-etching AdheSE primer, then oxalate application was performed. Smear layer compositions are similar to the originating tissue $(50 \%$ vol. minerals and $30 \%$ vol. collagen) ${ }^{[40,42]}$. The application of $\mathrm{NaOCl}$ to the smear layer would eliminate its collagen phase which would facilitate the penetration of the self-etch primer through water-filled channels between particles of smear layer enlarging them to reach the underlying mineralized dentin more easily [42].

Part of the demineralized dentin collagen may be in a denatured unstable state which is highly sensitive to hydrolysis $[43,40]$. Based on this assumption, $\mathrm{NaOCl}$ might have removed the organic content of smear layer as well as some organic content of the underlying dentin, thus decreasing the hydrophilic collagen within the dentinal surface with subsequent decrease in water sorption. The effect of $\mathrm{NaOCl}$ on smear layer-covered dentin was supported by other studies ${ }^{[42,59]}$.

Single-bottle self-etch adhesives are characterized by their increased 
hydrophilicity and decreased viscosity as they contain high concentration of HEMA and water/solvent combinations. The presence of the highly hydrophilic HEMA was advisable to improve wetting and spreading of adhesives on dentin as well as for maintaining dimethacrylates in solution and preventing phase separation ${ }^{[31,49,60-62]}$.

On the other hand, HEMA and other comonomers have been recently recognized to lower the vapor pressure of water and so prevent its complete removal from the adhesive during bonding and promote residual water in unstable soft hydrogels within both hybrid and adhesive layers $[49,60$, ${ }^{61]}$. Furthermore, such highly hydrophilic polymers are capable of imbibing large amount of water from the underlying dentin. Thus, absorbed water remains entrapped within the resin-dentin interface, that gradually increases over time. Such water plasticizes the polymers and degrades their mechanical properties. This may facilitate degradation of hydrophilic polymers (collagen and resin) that lowers the durability of resin-dentin interface ${ }^{[31,49,60 \text {, }}$ 63].

In an attempt to overcome problems created by HEMA, recent HEMA-free onestep self- etch adhesives, containing less hydrophilic comonomers, have been introduced. The omission of HEMA from the adhesive blends has been considered advantageous in preventing water sorption $[31,49,60,61]$. However, the absence of HEMA necessitates higher water/solvent content to maintain components in solution. The high acetone content (40\%) of the G-Bond may lower the viscosity of the solution, enhancing the penetration of the bonding agent into the demineralized collagen-rich dentin matrix, and may lower the surface tension of water due to its "water chasing" effect $^{[49,61]}$.

However, rapid acetone evaporation, allows increases in water concentration, causing phase changes in the comonomer blend. The recommended application time may not be enough for allowing water to diffuse upwards and be evaporated from the partially polymerized adhesive layer. Rapid acetone evaporation may lower the temperature of the comonomers, decreasing monomer diffusion rates ${ }^{[61]}$.

Due to the partial solubility of some resinous compounds (like UDMA), hydrophobic and hydrophilic-rich phases form. Phase separation within the HEMAfree adhesive may result in the separation of free water, not completely evaporated, within dimethacrylate-rich adhesive resin resulting in a porous bonded interface. Thus, vigorous air-drying of adhesive, prior to polymerization, according to the manufacturer's instructions is thought to be very important for removal of these water blisters $[31,48,59,60,61]$

On the other hand, the permeability results of the current study showed that GBond, when applied without any surface pretreatment, provided a permeable bonded interface that was even more permeable than that provided by the two-step HEMAcontaining self-etch adhesive AdheSE, although it was applied using vigorous drying ${ }^{[31,64]}$. The permeability of G-Bond adhesive may be attributed to the fact that vigorous air drying may induce evaporative water flux from dentin, allowing dentin water movement into the adhesive layer bonded to dentin. Water movement through the polymerized adhesive matrix may further generate additional pathways for water penetration, increasing water uptake.

In an attempt to improve dentinal sealing, acidic potassium oxalate was applied to smear layer-covered dentin, based on the assumption that G-Bond adhesive could produce chemical bonding with inorganic-rich substrate due to the presence of 4-methacryloxyethyl trimellitate (4MET) in its composition. Oxalate was not preceded by an etching step as this would increase permeability due to all problems associated with the etch-and-rinse technique, mainly smear layer removal and over-etching.

Unfortunately, oxalate pretreatment resulted in a significant increase in permeability when compared to dentin discs 
treated with G-Bond adhesive without any surface pretreatment. This may be attributed to the fact that application of the slightly acidic ( $\mathrm{pH}=2.5$ ) oxalate solution on smear layer, transforms the dentin surface from an acid-labile to an acid-resistant structure, probably due to the removal of the original smear layer by etching and its replacement by an acid-resistant layer of calcium oxalate crystals and calcium phosphate crystals ${ }^{[30]}$. Calcium ions needed to form calcium oxalate crystals are obtained from calcium in the mineral phase of the smear layer. Although, these insoluble crystals probably reduce dentin permeability, they are highly resistant to demineralization which created an obstacle for adhesive penetration into the dentinal surface especially when using the weakly acid G-Bond adhesive.

The self-etching conditioning effect of G-Bond adhesive might have resulted in loose oxalate crystals within the bonded interface. These loose crystals might have decreased the wettability as well as the bonded surface area. Consequently, the bonding efficiency of G-Bond may have been adversely affected. This was in agreement with the results of Yiu, et al. ${ }^{[14]}$, who reported that loose crystals within the bonded interface may also act as stressraisers which would, in turn, create debonding at lower stresses.

However, in the current study when $\mathrm{NaOCl}$ treatment preceded oxalate application in the G-Bond group, the dentin permeability decreased significantly when compared to oxalate pretreatment alone. This may be attributed to the production of a relatively porous smear layer due to removal of its organic content. Such effect might have, somehow, facilitated the resin penetration into dentin after precipitation of the calcium oxalate crystals with slightly improved micro-mechanical retention. Thus, it may be suggested that the interaction of G-Bond with dentin depends mainly on micromechanical interlocking rather than chemical bonding. Furthermore, reducing the collagen content might have reduced the water content of the bonded interface.

\section{Effect of aging on bond durability}

Degradation of resin-dentin bonds by aging may be attributed to continuous fluid transudation from the underlying dentin into the bonded interface, under positive pulpal pressure. Consequently, fluid may continue to pass into the bonded interface via leaky resin tags, defective hybridization and porosities within the adhesive. On the other hand, another timedependent effect is the slow hydrolytic action of the endogenous matrix metalloproteinases such as MMP-2,-8,-9 and-20. These endogenous enzymes have collagenolytic and telopeptidase activity which may further contribute to the degradation of the hybrid layer ${ }^{[23,65-71]}$. What used to be regarded as hybrid layer degradation due to elution of unpolymerized resins may have been due to slow degradation of collagen by endogenous matrix proteases ${ }^{[72]}$. Thus, storage for two months produced time-dependent water sorption and subsequent hydrolytic degradation that was reflected by significant increases in permeability results of all subgroups of this study (Table 2).

Degradation of both collagen and hydrophilic resin might have occurred, but to a lesser extent, when calcium oxalate crystals were formed within the bonded interface. This may be attributed to less fluid transudation from the occluded dentinal tubules and/or sealed hybrid layers (supported by permeability results, Table 2).

Collagen removal by $\mathrm{NaOCl}$ pretreatment in this study resulted in a more durable resin-dentin interfaces, which were reflected by significant decreases in permeability results when comparing 2month oxalate alone pretreatment results with 2-month $\mathrm{NaOCl}$ and oxalate pretreatment results. Thus, resin retention based on resin infiltration of collagen fibrils has been shown to be unstable over time ${ }^{[41 \text {, }}$ $42,44,65-71,73]$ 


\section{CONCLUSIONS}

Based on the results of this study, it can be concluded that:

1. None of the tested adhesives could provide an impervious seal of deep dentin surfaces after 24-hour storage period (except for AdheSE using $\mathrm{NaOCl}$ + oxalate pretreatment).

2. Storage for two months increased the permeability of the bonded interfaces of all subgroups with varying degrees reaching its minimum with $\mathrm{NaOCl}+$ oxalate pretreatment of AdheSE group.

3. Bonding technique plays a critical role in the sealing capacity of different adhesives.

4. The two-step self-etch adhesive (AdheSE), used in this study, was the best sealing adhesive material.

5. The HEMA-free adhesive (G-Bond), used in this study, did not provide better sealing of dentin surfaces.

6. Oxalate application was able to improve the sealing of the dentin surfaces when used in conjunction with the two-step etch-and-rinse and the two-step self-etch adhesives, but impaired dentinal sealing when used with the one-step self-etch GBond adhesive.

7. Dentin deproteinization may improve resin-dentin adhesion and reduce bonded-interface permeability. This emphasizes the negative role of the collagen fibril matrix in bond degradation and reduced durability of resin-dentin bonds.

\section{Acknowledgement: None}

\section{Conflict of Interest: None}

\section{Source of Funding: None}

\section{Ethical Approval: Approved}

\section{REFERENCES}

1. Scotti N, Cavalli G, Gagliani M, Breschi L. New adhesives and bonding techniques. Why and when? International
Journal of Esthetic Dentistry 2017; 12(4): 524-535.

2. Chersoni S, Suppa P, Grandini S, Goracci C, Monticelli F, Yiu C, et al. In-vivo and in-vitro permeability of one-step self-etch adhesives. Journal of Dental Research 2004; 83(6): 459-464.

3. Vaysman T, Rajan N, Thompson VP. Effect of bur cutting patterns and dentin bonding agents on dentin permeability in a fluid flow model. Operative Dentistry 2003; 28(5): 522-528.

4. Escribano N, Del-Nero O, De La Macorra JC. Sealing and dentin bond strength of adhesive systems in selected areas of perfused teeth. Dental Materials 2001; 17: 149-155.

5. Cadenaro M, Antoniolli F, Sauro S, Tay FR, Di Lenarda R, Prati C, et al. Degree of conversion and permeability of dental adhesives. European Journal of Oral Sciences 2005; 113: 525-530.

6. Tay FR, Frankenberger R, Krejci I, Bouillaguet S, Pashley DH, Carvalho RM, et al. Single-bottle adhesives behave as permeable membranes after polymerization. I. In-vivo evidence. Journal of Dentistry 2004; 32: 611-621.

7. Reis AF, Giannini M, Pereira PNR. Influence of water-storage time on the sorption and solubility behavior of current adhesives and primer / adhesive mixtures. Operative Dentistry 2007; 32(1): 53-59.

8. Chersoni S, Suppa P, Breschi L, Ferrari M, Tay FR, Pashley DH, et al. Water movement in the hybrid layer after different dentin treatments. Dental Materials 2004; 20: 796-803.

9. Pashley DH, Tay FR, Breschi L, Tjaderhane L, Carvalho RM, Carrilho M, et al. State of the art etch-and-rinse adhesives. Dental Materials 2011; 27:116.

10. Tay FR, Pashley DH, Yiu C, Cheong C, Hashimoto M, Itou K, et al. Nanoleakage types and potential implications: Evidence from unfilled and filled adhesives with the same resin composition. American Journal of Dentistry 2004; 17: 182-190.

11. Tay FR, Pashley DH, Suh B, Carvalho R, Miller M. Single-step, self-etch adhesives behave as permeable membranes after 
polymerization. Part I. Bond strength and morphologic evidence. American Journal of Dentistry 2004; 17: 271-278.

12. Leme AFP, Santos JC RG, Giannini M, Wada RS. Occlusion of dentin tubules by desensitizing agents. American Journal of Dentistry 2004; 17: 368-372.

13. Elgalaid TO, Youngson CC, Mc Hugh S, Hall AF, Creanor SL, Foye RH. In-vitro dentin permeability: The relative effect of a dentin bonding agent on crown preparations. Journal of Dentistry 2004; 32: 413-421.

14. Yiu CKY, King NM, Suh BI, Sharp LJ, Carvalho RM, Pashley DH, et al. Incompatability of oxalate desensitizers with acidic fluoride-containing total-etch adhesive. Journal of Dental Research 2005; 84(8): 730-735.

15. Pashley DH, Carvalho RM, Pereira JC, Villanueva R, Tay FR. The use of oxalate to reduce dentin permeability under adhesive restorations. American Journal of Dentistry 2001; 14(2): 89-94.

16. NG LP, Wilson PR. The effects of phosphoric acid, sodium hypochlorite, ferric oxalate and Scotchbond Multipurpose on the rate of pressure change across dentin: a laboratory study. Journal of Oral Rehabilitation 2005; 32: 418-426.

17. Gillam DG, Mordan NJ, Sinodinou AD, Tang JY, Knowles JC, Gibson IR. The effects of oxalate-containing products on the exposed dentin surface: a SEM investigation. Journal of Oral Rehabilitation 2001; 1037-1044.

18. Tay FR, Pashley DH, Mak YF, Carvalho RM, Lai SCN, Suh BI. Integrating oxalate desensitizers with total-etch two-step adhesive. Journal of Dental Research 2003; 82(9): 703-707.

19. Carrilho MR, Tay FR, Sword J, Donnelly AM, Agee KA, Nishitani Y, Sadek FT, Carvalho RM, Pashley DH. Dentin sealing provided by smear layer/ smear plugs vs adhesive resin/resin tags. European Journal of Oral Sciences 2007; 115: 321329.

20. Seara SF, Erthal BS, Ribeiro M, Kroll L, Pereira GDS. The influence of a dentin desensitizer on the microtensile bond strength of two bonding systems. Operative Dentistry 2002; 27: 154-160.

21. Sauro S, Watson TF, Tay FR, Chersoni S, Breschi L, Bernardi F, et al. Water uptake of bonding systems applied on root dentin surfaces: A SEM and conofocal microscopic study. Dental Materials 2006; 22: 671-680.

22. Yiu CKY, Hiraishi N, Chersoni S, Breshi L, Ferrari M, Prati C, et al. Single-bottle adhesives behave as permeable membranes after polymerization II. Differential permeability reduction with an oxalate desensitizer. Journal of Dentistry 2006; 34: 106-116.

23. Tjäderhane L, Nascimento FD, Breschi L, Mazzoni A, Tersariol ILS, Geraldeli S, et al. Optimizing dentin bond durability: Control of collagen degradation by matrix metalloproteinases and cysteine cathepsins. Dental Materials 2013; 19: 116-135.

24. Hashimoto M. A review micromorphological evidence of degradation in resin-dentin bonds and potential preventional solutions. Journal of Biomedical Materials Research: Part B, Applied Biomaterials 2010; 92:268-80.

25. Botta SB. What causes durability reduction in tooth-colored resin restorations? Journal of Contemporary Dental Practice 2012; 13: i-ii.

26. Breschi L, Mazzoni A, Ruggeri A, Cadenaro M, Di Lenarda R, De Stefano Dorigo E. Dental adhesion review: aging and stability of the bonded interface. Dental Materials 2008; 24:90-101.

27. Liu Y, Tjäderhane L, Breschi L, Mazzoni $\mathrm{A}, \mathrm{Li} \mathrm{N}$, Mao J, et al. Limitations in bonding to dentin and experimental strategies to prevent bond degradation. Journal of Dental Research 2011; 90:953968.

28. Mazzoni A, Angeloni V, Apolonio FM, Scotti N, Tjaderhane L, TezvergilMutluay A, et al. Effect of carbodiimide (EDC) on the bond stability of etch and rinse adhesive systems. Dental Materials 2013; 29:1040-1047.

29. Pashley DH, Pashley El, Carvalho RM, Tay FR. The effect of dentin permeability 
on restorative dentistry. Dental Clinics of North America 2002; 46: 211-245.

30. Pashley DH, Galloway SE. The effects of oxalate treatment on the smear layer of ground surfaces of human dentin. Archives of Oral Biology 1985; 30(10): 731-737.

31. Sauro S, Pashley DH, Montanari M, Chersoni S, Carvalho RM, Toledano M, et al. Effect of simulated pulpal pressure on dentin permeability and adhesion of selfetch adhesives. Dental Materials 2007; 23 : 705-713.

32. Hashimoto M, Tay FR, Svizero NR, De Gee AJ, Feilzer AJ, Sano H, et al. The effects of common errors on sealing ability of total-etch adhesives. Dental Materials 2006; 22: 560-568.

33. Hashimoto M, Ito S, Tay FR, Svizero NR, Sano H, Kaga M, et al. Fluid movement across the resin-dentin interface during and after bonding. Journal of Dental Research 2004; 83(11): 843-848.

34. Breschi L, Cadenaro M, Antoniolli F, Sauro S, Biasotto $M$, Prati $C$, et al. Polymerization kinetics of dental adhesives cured with LED: Correlation between extent of conversion and permeability. Dental Materials 2007; 23: 1066-1072.

35. Hashimoto M, Nagano F, Endo K, Ohno H. A review: Biodegradation of resindentin bonds. Japanese Dental Science Review 2011; 47: 5-12.

36. Breschi L, Maravic T, Comba A, Cunha $\mathrm{SR}$, Loguercio $\mathrm{AD}$, Reis A, Hass $\mathrm{V}$, Cadenaro M, Mancuso E, Mayer-Santos E, Niu L, Pashley DH, Tay FR, Mazzoni A. Chlorhexidine preserves the hybrid layer in vitro after 10-years aging. Dental Materials 2020;36(5):672-680.

37. Pashley DH, Tay FR. Have dentin adhesives become too hydrophilic? Journal of Canadian Dental Association 2003; 69(11): 726-731.

38. Toledano M, Perdigao J, Osorio R, Osorio E. Effect of dentin deproteinization on microleakage of class $\mathrm{V}$ composite restorations. Operative Dentistry 2000; 25: 497-504.

39. Sato H, Miyazaki M, Moore BK. Influence of $\mathrm{NaOCl}$ treatment of etched and dried dentin surface on bond strength and resin infiltration. Operative Dentistry 2005; 30(3): 353-358.

40. Muniz L, Mathias P. The influence of sodium hypochlorite and root canal sealers on post retention in different dentin regions. Operative Dentistry 2005; 30(4): 533-539.

41. Saboia VPA, Almeida PC, Ritter AV, Swift Jr EJ, Pimenta LAF. 2-year clinical evaluation of sodium hypochlorite treatment in the restoration of non carious cervical lesions: a pilot study. Operative Dentistry 2006; 31(5): 530-535.

42. Montez MAJR, De Goes MF, Ambrosano GHB, Duarte RM, Sobrinho LC. The effect of collagen removal and the use of a low-viscosity resin liner on marginal adaptation on resin composite restorations with margins in dentin. Operative Dentistry 2003; 28(4): 378-387.

43. Josic U, Maravic T, Mazzitelli C, Del Bianco F, Mazzoni A, Breschi L. The effect of chlorhexidine primer application on the clinical performance of composite restorations: a literature review. Journal of Esthetic Restorative Dentistry 2021;33 (1):69-77.

44. Inoue S, Murata Y, Sano H, Kashiwada T. Effect of $\mathrm{NaOCl}$ treatment on bond strength between indirect resin core-build up and dentin. Dental Materials 2002; 21(4): 343-354.

45. Prati C, Chersoni S, Pashley DH. Effect of removal of surface collagen fibrils on resin-dentin bonding. Dental Materials 1999; 15(5): 323-331.

46. Van Meerbeek B, De Munck J, Yoshida $\mathrm{Y}$, Inoue $\mathrm{S}$, Vargas $\mathrm{M}$, Vijay $\mathrm{P}$. Buonocore memorial lecture. Adhesion to enamel and dentin: current status and future challenges. Operative Dentistry 2003; 28(3): 215-235.

47. Maeda T, Yamaguchi K, Takamizawa T, Rikuta A, Tsubota K, Ando S, et al. pH changes of self-etching primers mixed with powdered dentine. Dental Materials 2008; 36:606-10.

48. Yuan Y, Shimada Y, Ichinose S, Tagami J. Qualitative analysis of adhesive interface nanoleakage using FE- 
SEM/EDS. Dental Materials 2007; 23: 561-569.

49. Pashley EL, Zhang Y, Lockwood P, Rueggeberg F, Pashley DH. Effects of HEMA on water evaporation from waterHEMA mixtures. Dental Materials 1998; 14: 6-10.

50. Ozok AR, Wu MK, De Gee AJ, Wesselink PR. Effect of dentin perfusion on the sealing ability and microtensile bond strengths of a total-etch versus an all-in-one adhesive. Dental Materials 2004; 20: 479-486.

51. Owens BM, Johnson WW. Effect of single-step adhesives on the marginal permeability of class $\mathrm{V}$ resin composites. Operative Dentistry 2007; 31(2): 67-72.

52. Owens BM, Johnson WW, Harris EF. Marginal permeability of self-etch and total-etch adhesive systems. Operative Dentistry 2006; 31(1): 60-67.

53. Reis AF, Giannini M, Pereira PNR: Long-term TEM analysis of the nanoleakage patterns in resin-dentin interfaces produced by different bonding strategies. Dental Materials 2007; 23: 1164-1172.

54. Asaka Y, Miyazaki M, Takamizawa T, Tsubota K, Moore BK. Influence of delayed placement of composites over cured adhesives on dentin bond strength of single-application self- etch systems. Operative Dentistry 2006; 31(1): 18-24.

55. Gregoire G, Millas A. Microscopic evaluation of dentin interface obtained with 10 contemporary self-etching systems: correlation with their $\mathrm{pH}$. Operative Dentistry 2005; 30(4): 481-491.

56. Itthagarun A, Tay FR, Pashley DH, Wefel JS, Garcia-Godoy F, Wei SHY. Singlestep, self-etch adhesives behave as permeable membranes after polymerization. Part III. Evidence from fluid conductance and artificial caries inhibition. American Journal of Dentistry 2004; 17: 394-400.

57. Tay FR, Pashley DH, Peters MC. Adhesive permeability affects composite coupling to dentin treated with a self-etch adhesive. Operative Dentistry 2003; 28(5): 610-621.
58. Thonemann B, Federlin M, Schmalz G, Grundler W. Total bonding vs selective bonding: marginal adaptation of class II composite restorations. Operative Dentistry 1999; 24: 261-271.

59. Lee B-S, Hsieh T-T, Chi D C-H, Lan W$\mathrm{H}$, Lin C-P. The role of organic tissue on the punch shear strength of human dentin. Journal of Dentistry 2004; 32: 101-107.

60. De Munck J, Ermis RB, Koshiro K, Inoue $\mathrm{S}$, Ikeda $\mathrm{T}$, Sano $\mathrm{H}$, et al. $\mathrm{NaOCl}$ degradation of a HEMA-free all-in-one adhesive bonded to enamel and dentin following two air-blowing techniques. Journal of Dentistry 2007; 35: 74-83.

61. Monticelli F, Osorio R, Pisani-Proença J, Toledano M. Resistance to degradation of resin-dentin bonds using a one-step HEMA-free adhesive. Journal of Dentistry 2007; 35: 181-186.

62. Sauro S, Mannocci F, Toledano M, Osorio $\mathrm{R}$, Thompson I, Watson TF. Influence of the hydrostatic pulpal pressure on droplets formation in current etch-and-rinse and self-etch adhesives: a video rate/TSM microscopy and fluid filtration study. Dental Materials 2009; 25:1392-402.

63. Hashimoto M, Fujita S, Kaga M, Yawaka Y. Effect of dentinal water on bonding of one-bottle self-etching adhesives. Dental Materials 2008; 27:172-8.

64. Hashimoto M, Fujita S, Endo K, Ohno H. In vitro degradation of resin-dentin bonds with one-bottle self- etching adhesives. European Journal of Oral Sciences 2009; 117:611-7.

65. Tay FR, Hashimoto M, Pashley DH, Peters MC, Lai SCN, Yiu CKY, et al. Aging affects two modes of nanoleakage expression in bonded dentin. Journal of Dentistry 2003; 82(7): 537-541.

66. Hebling J, Pashley DH, Tjaderhane L, Tay FR: Chlorhexidine arrests subclinical degradation of dentin hybrid layers invivo. Journal of Dental Research 2005; 84: 741-746.

67. Mazzoni A, Pashley DH, Tay FR, Gobbi $\mathrm{P}$, Orsini G, Ruggeri Jr A, et al. Immunohistochemical identification of MMP-2 and MMP-9 in human dentin: correlative FEI-SEM/TEM analysis. 
Journal of Biomedical Materials Research 2009; 88:697-703.

68. Toledano M, Nieto-Aguilar R, Osorio R, Campos A, Osorio E, Tay FR, et al. (2010). Differential expression of matrix metalloproteinase-2 in human coronal and radicular sound and carious dentine. Journal of Dentistry 2010; 38: 635-640.

69. Mazzoni A, Papa V, Nato F, Carrilho M, Tjäderhane L, Ruggeri A, et al. Immunohistochemical and biochemical assay of MMP-3 in human dentine. Journal of Dentistry 2011; 39:231-237.

70. Osorio R, Yamauti M, Osorio E, RuizRequena ME, Pashley D, Tay F, et al. Effect of dentin etching and chlorhexidine application on metalloproteinase-mediated collagen degradation. European Journal of Oral Science 2011; 119:79-85.

71. Mazzoni A, Nascimento FD, Carrilho M, Tersariol I, Papa V, Tjäderhane L, et al.
Matrix metalloproteinase (MMP) activity in the hybrid layer detected with in situ zymography. Journal of Dental Research 2012; 91:467-472.

72. Abdalla AI, Feilzer AJ. Four-year water degradation of a total etch and two selfetching adhesives bonded to dentin. Journal of Dentistry 2008; 36: 611-7.

73. De Munck J, Shirai K, Yoshida Y, Inoue S, Van Landuyt KL, Lambrechts $\mathrm{P}$, et al. Effect of water storage on the bonding effectiveness of 6 adhesives to class I cavity dentin. Operative Dentistry 2006; 30(1): 456-465.

How to cite this article: Manar M Abu Nawareg, Ola I Fahmy, Gihan A Abdel Rahman et.al. Permeability of modified dentinal surfaces. Int J Health Sci Res. 2021; 11(4): 272-287. DOI: https://doi.org/ 10.52403/ijhsr.20210432 